\title{
O ATIVISMO TRANSNACIONAL ANARQUISTA NO SUL DO CONTINENTE AMERICANO: UM EXEMPLO DE REGIONOFILIA LIBERTÁRIA
}

\author{
Rafael Zilio Fernandes* \\ Universidade Federal do Oeste do Pará
}

Resumo: 0 artigo analisa as relações entre ativistas organizados em torno de três Federações Anarquistas situadas em Rosário (Argentina), Montevidéu (Uruguai) e Porto Alegre (Brasil), relações estas auxiliadas pela histórica (e geográfica) proximidade simbólico-cultural e política entre os países do Prata e o estado brasileiro do Rio Grande do Sul. Primeiramente contextualizo a pesquisa que apresentou tais resultados, o conceito em construção regionofilia e o advento das Federações Anarquistas. Após, são evidenciadas as vozes de ativistas das Federações a respeito de quatro tópicos: a fronteira; o universo valorativo gaucho; relações entre a identidade sócio-espacial gaucha, o anarquismo e as lutas sociais; e as relações entre as três organizações. Finalizo ponderando que o caso estudado constitui um exemplo de regionofilia antinacionalista e, mais especificamente, apresenta uma regionofilia libertária.

Palavras-chave: Ativismo Transnacional. Federações Anarquistas. Regionofilia. Identidade Sócio-Espacial Gaucha. Sul do Continente Americano.

THE ANARCHIST TRANSNATIONAL ACTIVISM IN THE SOUTH OF THE AMERICAN CONTINENT: AN EXAMPLE OF LIBERTARIAN REGIONOPHILIA

Abstract: The paper analyses the relations between activists organized in three Anarchist Federations at Rosario (Argentina), Montevideo (Uruguay) and Porto Alegre (Brazil), stimulated by the historical (and geographical) symbolic-cultural and political proximity among the countries of the Plata and the Brazilian state of Rio Grande do Sul. First I contextualize the investigation that presented such results, the concept in construction regionophilia, and the emergency of the Anarchists Federations. After, I approach the voices of the activists of the Federations focusing on four topics: the border; the gaucho valuation universe; relations between the gaucha socio-spatial identity, the anarchism and social struggles; and the relations between the three organizations. I end by pondering that the case is an example of anti-nationalist regionophilia and, more specifically, it presents a libertarian regionophilia.

Keywords: Transnational Activism. Anarchist Federations. Regionophilia. Gaucha Socio-Spatial Identity. South of the American Continent.

\section{EL ACTIVISMO TRANSNACIONAL ANARQUISTA EN EL SUR DEL CONTINENTE AMERICANO: UN EJEMPLO DE REGIONOFILIA LIBERTARIA}

Resumen: El artículo analiza las relaciones entre activistas organizados en torno a tres Federaciones Anarquistas situadas en Rosario (Argentina), Montevideo (Uruguay) y Porto Alegre (Brasil), relaciones esas amparadas por la histórica (y geográfica) proximidad simbólico-cultural y política entre los países del Plata y el estado brasileño de Rio Grande do Sul. En primero yo contextualizo la investigación que presentó esos resultados, el concepto en construcción regionofilia y el adviento de las Federaciones Anarquistas. Después, se evidencian las voces de activistas de las Federaciones sobre cuatro temas: la frontera; el universo valorativo gaucho; las relaciones entre la identidad socio-espacial gaucha, el anarquismo y las luchas sociales; y las relaciones entre esas tres organizaciones. Finalizo ponderando que el caso estudiado constituye un ejemplo de regionofilia antinacionalista y, más específicamente, presenta una regionofilia libertaria.

Palabras clave: Activismo Transnacional. Federaciones Anarquistas. Regionofilia. Identidade Socio-Espacial. Sur del Continente Americano. 
Introdução

A retomada do pensamento e da práxis libertários por movimentos sociais emancipatórios e por intelectuais em diversas partes do globo na segunda metade do século $X X$ deparou-se com desafios que na época do anarquismo clássico ou estavam em fase embrionária ou simplesmente inexistiam ${ }^{\prime}$. Os limites geográficos do internacionalismo, no passado, apresentaram-se na medida em que os militantes e pensadores europeus se limitaram em grande parte a pensar apenas uma Europa federada. Com a mobilidade populacional intercontinental, não somente as significações imaginárias capitalistas chegam às Américas, mas também as significações anticapitalistas libertárias que terão capilaridade no tecido social de norte a sul do continente em maior ou menor grau. 0 resgate de formas organizacionais e valores anticapitalistas nas lutas sociais latino-americanas a partir da década de 1980 na esteira da decadência dos modelos inspirados no marxismo-leninismo deu-se em um mundo em processo de globalização, em que os avanços técnicos repercutidos nos meios de transporte e de comunicação conformaram a base para a expansão geográfica do capitalismo concomitantemente às possibilidades de utilização dessa técnica por lutadores e lutadoras em distantes paragens e diferentes países. Apesar de os contextos geográficos e culturais serem diferentes, as contradições do capitalismo, em especial a relação capital-trabalho, são as mesmas, a despeito de outras pautas terem emergido ao longo das últimas décadas. Um exemplo de ativismo que se transnacionaliza é encontrado no caso de Federações Anarquistas situadas ao sul do continente americano.

Este artigo é fruto de minha tese de doutorado que analisou relações entre a identidade sócioespacial gaucha ${ }^{2}$ e o pensamento e a práxis libertários na Argentina, no Uruguai e no estado brasileiro do Rio Grande do Sul. Desse estudo resultou o "conceito em construção" regionofilia, que é, em poucas palavras, o sentimento de pertencimento a uma determinada região mobilizado para intentos políticos e que, comumente, serve de suporte para regionalismos conservadores. Contudo, a pesquisa em questão evidenciou uma regionofilia libertária no referencial empírico capitaneada por ativistas organizados em torno da Federación Anarquista de Rosario (FAR), da Federación Anarquista

10 pensamento e a práxis libertários caracterizam-se por uma multiplicidade de correntes e perspectivas que vão desde o anarquismo clássico, passando pelo neoanarquismo e pelo autonomismo contemporâneos. O que tais perspectivas têm em comum é, ao mesmo tempo e entre outras coisas, a rejeição simultânea do modelo civilizatório capitalista (Estado capitalista incluso) e das alternativas burocrático-centralistas advindas do marxismo-leninismo. Para maior aprofundamento, ver Souza (2017)

2Para a compreensão da complexidade da identidade sócio-espacial gaucha ver, entre outros textos, Zilio (2016)
Uruguaya (FAU) e da Federação Anarquista Gaúcha (FAG). No presente texto destaco a construção do ativismo transnacional anarquista no sul do continente americano que se serve das históricas (e geográficas) relações transfronteiriças para seu estabelecimento, ora se aproximando do universo valorativo gaucho ${ }^{3}$, ora criticando-o.

Primeiramente contextualizo 0 advento das Federações Anarquistas nesta parte do globo. Após, são evidenciadas as vozes de ativistas das Federações a respeito de quatro tópicos: a fronteira; o universo valorativo gaucho; relações entre a identidade sócioespacial gaucha, o anarquismo e as lutas sociais; e as relações entre as três organizações. Finalizo ponderando que o caso estudado constitui um exemplo de regionofilia antinacionalista e, mais especificamente, apresenta uma regionofilia libertária.

\section{0 advento das Federações Anarquistas}

No Uruguai, país onde o pensamento libertário encontrou abrigo no campo e na cidade ao longo do século $X X$, a classe trabalhadora experimentou um crescimento considerável em número e em capacidade organizacional a partir da década de 1940, momento de forte êxodo rural com a chegada de trabalhadores rurais de tradição bipartidária (Blancos ou Colorados) e paternalista. Isso foi um desafio às organizações de trabalhadores urbanas que contavam com uma quantidade expressiva de imigrantes de tendência libertária e com experiência organizacional há decênios. A concepção anarcossindicalista dominante na Federación Obrera Regional Uruguaya (FORU), assim como na Federación Obrera Regional Argentina (FORA), entendia o sindicato como espaço primordial de organização da classe trabalhadora e de gestação de uma nova sociedade, sendo a busca do "comunismo libertário" recomendada em seu estatuto (ALVES, 2016). Contudo, apenas um quase inexpressivo número de trabalhadores estava filiado à FORU, enquanto outras entidades mais reformistas cresciam. Nesse contexto alguns militantes começaram a montar "sindicatos autônomos", núcleos anarquistas onde emergiu o debate sobre a criação de organizações especificamente anarquistas, sem a necessidade de atrelamento visceral com qualquer outro tipo de organização como sindicatos, sob inspiração de escritos principalmente de Bakunin e Malatesta. Com o passar dos anos diversas greves e lutas operárias

${ }^{3} \mathrm{O}$ universo valorativo gaucho é uma miríade de símbolos, valores, hábitos e costumes que permeia a identidade sócio-espacial gaucha, já explorado em trabalho anterior (ZILIO, 2016). Tais elementos podem ser desde costumes cotidianos como tomar un mate ou andar a cavalo até significações contestatórias. Para este trabalho, interessam valores críticos de cunho sócio-político como a insubordinação, a insubmissão a patrões e à propriedade privada rural, dentre outros. 
ocorreram no Uruguai sem o devido apoio da principal união sindical uruguaia, de tendência comunista, mais empenhada em pleitear cargos em eleições e dar apoio à URSS (idem), e micro-organizações pulularam para dar conta da solidariedade classista necessária naquele momento. 0 território dissidente Ateneo Cerro-La Teja destacou-se nos anos 1950 por, além de promover debates e articular lutas, oferecer formação educacional e cultural para seus participantes, onde nomes como Alfredo Zitarrosa e Carlos Molina se apresentaram.

0 acúmulo de experiência da militância anarquista uruguaia, bem como as discussões sobre a necessidade de fundação de uma organização anarquista específica, resultou na fundação da Federación Anarquista Uruguaya em outubro de 1956, com sede no referido Ateneo durante os primeiros anos de existência, até ser posta em clandestinidade pelo governo Pacheco Areco (19671972), considerado uma ditadura constitucional préregime militar. Das lutas anteriores à sua fundação até a consolidação estrutural surge o anarquismo especifista, ou simplesmente especifismo, uma estratégia de organização que visa à criação de organizações especificamente anarquistas para potencializar a inserção nos movimentos sociais. Corrêa (2013) destaca dois eixos de constituição da estratégia: organização e inserção a nível político e social em Bakunin e a organização específica anarquista em Malatesta. Sabese que o anarquismo apresenta diversas correntes em seu interior, entre elas algumas individualistas e que não primam pela organização social, por isso a carta de princípios da FAU destaca a necessidade organizativa:

Nuestra crítica y nuestro proyecto no se agotan
en el levantamiento, la protesta y la rebelión sino
que maduran en un modelo de sociedad libertaria
inconfundiblemente socialista, en una estrategia
de ruptura revolucionaria y en un estilo militante
combativo y de agitación permanente en dirección
a las transformaciones sociales en gran escala. Este
proyecto se canaliza a través de la organización
revolucionaria específica y es por tanto, lucha
organizada. (Federación Anarquista Uruguaya, 1993,
não paginado)

Não é meu intuito pormenorizar o especifismo aqui, apenas apresentá-lo em linhas gerais, uma vez que esta estratégia será comum no ativismo transnacional abordado neste texto. Interessa, pois, saber que a FAU expandiu grandemente sua influência nos meios libertários da América do Sul a partir da segunda metade do século $X X$. Hoje existem inúmeras organizações anarquistas especifistas em alguns países vizinhos e também em diversos estados brasileiros, do Rio Grande do Sul ao Pará4, estes federados em torno da

"${ }^{4}$ Exemplos: Federação Anarquista Cabana (FACA-Belém), Federação Anarquista dos Palmares (FARPA-Maceió), Federação Anarquista do Rio de Janeiro (FARJ), Coletivo Mineiro Popular Anarquista (COMPA-Belo Horizonte), Coletivo Anarquista
Coordenação Anarquista Brasileira (CAB).

$\mathrm{Na}$ esteira dessa influência, em 1995 surge a Federação Anarquista Gaúcha, situada na área central da cidade de Porto Alegre, em que, até os dias atuais, seus membros relacionam-se fortemente com a FAU. A mais nova organização em questão, a Federación Anarquista de Rosario, data de 2008 e, como veremos, possui mais relações com a Federação brasileira do que com a organização uruguaia.

As falas dos ativistas das Federações Anarquistas: fronteira, identidade e transnacionalismo

As relações entre FAU-Montevidéu, FAG-Porto Alegre, e FAR-Rosário são centrais para se entender a transnacionalidade do pensamento e da práxis libertários atualmente na região transnacional gaucha ${ }^{5}$. Metodologicamente, procedeu-se pela abordagem de ativistas das três organizações via recurso da história oral com posterior análise dos discursos dos mesmos, uma vez que vários elementos importantes para a pesquisa jamais foram documentados, apenas aparecem na oralidade daqueles e daquelas que participam das Federações. Realizou-se um total de quatro entrevistas, sendo duas na FAG, uma na FAU e uma na FAR ${ }^{6}$. O roteiro das entrevistas foi o seguinte:

- Origens pessoais (de onde é);

- Começo da militância e identificação com o anarquismo;

- Relações com as demais Federações Anarquistas;

- A fronteira;

- O gaucho e possível identificação pessoal;

- Relações possíveis entre o universo gaucho e o anarquismo/lutas sociais.

Para destacar as falas e as ideias dos ativistas, foram elaboradas caixas com quatro assuntos principais nessa ordem:

- Fronteira;

- Universo valorativo gaucho;

- Relações entre a identidade sócio-espacial gaucha, o anarquismo e as lutas sociais;

\footnotetext{
Bandeira Negra (CABN-Florianópolis).

${ }^{5} \mathrm{~A}$ região transnacional gaucha é, resumidamente, uma regionalização que indica a mobilização de elementos do universo valorativo gaucho para propósitos políticos e que, grosso modo, corresponde ao referencial empírico em questão. Seus principais pressupostos são: é definida a partir do agente social gaucho e da identidade sócio-espacial gaucha em constante transformação ao longo do tempo até o presente, ainda que o universo valorativo gaucho esteja hoje demasiado transformando nos três países; a identidade sócio-espacial gaucha enquanto identidade transnacional, possuindo um componente além-fronteiras estatais; é berço de uma regionofilia cultivada por diferentes grupos; apresenta a mobilização de elementos do universo valorativo gaucho por grupos situados em diferentes pontos do espectro político; forma outras fronteiras, não estatais, mas que também são políticas. Para mais detalhes, ver Zilio (2014 e 2016).

${ }^{6}$ Em função de solicitação do entrevistado da FAR, a conversa ocorreu em português, porém a riqueza do portunhol foi mantida na transcrição.
} 
- E o ativismo transnacional FAG-FAU-FAR.

A fronteira (Caixa 1), referencial espacial muito presente no universo valorativo gaucho e também historicamente alvo de críticas dos libertários, é vista ao mesmo tempo como limitadora e como potencializadora de sociabilidades entre sujeitos oficialmente tidos pelo Estado como pertencentes a territórios diferentes. $\mathrm{Na}$ fronteira tem-se um "laboratório de formação cultural" e, para além de uma ideia de encontro, forma-se um "sujeito diferenciado" - o fronteiriço - em um contexto peleado, visto por outsiders ${ }^{7}$ como embrutecido e rude ("briguento"). A fronteira torna-se um espaço de convivência entre pessoas pretensamente separadas por uma linha imaginária e que guarda muitos elementos que combatem sociocentrismos como o nacionalismo.
Éuma região-lugar dentro da região transnacional gaucha ("Pra mim a fronteira sempre foi um pedaço de casa"). Sendo assim, contesta-se a divisão territorial do Estado na zona fronteiriça questionando-se "quem estabelece esse limite?" e os motivos pelos quais as pessoas que vivem tão próximas possuem nacionalidades diferentes. Por outro lado, a fronteira também é limitação, disciplinarização e controle dos corpos e das mentes, tornando-se inadequada sua naturalização ("un tanto institucionalizados, naturalizadas, cerca de la noción de límite como herramienta disciplinadora de las mientes"), enxergando-se as fronteiras como invenções dos Estados e mais problemáticas ainda no contexto da América Latina. As fortes interações entre as populações fronteiriças, nesse sentido, demonstram a

Caixa 1 - Fronteira segundo ativistas das Federações Anarquistas.

\section{FRONTEIRA}

"Pra mim é meio que um laboratório da minha formação cultural. Essa coisa da família misturada - um pedaço no Brasil, um pedaço no Uruguai. A fronteira pra mim sempre foi uma espécie de visita das famílias. 'Vou lá ver a minha família do Uruguai, depois vou lá ver minha família do Brasil'. Pra mim sempre foi muito divertida a fronteira, nunca associei a esse tipo de coisa. E sem falar que a linguagem da fronteira é muito específica, e como se identificam alguns códigos culturais muito fortes e marcantes. Em termos gerais claro, a gente vai fazer uma crítica grande às necessidades das fronteiras, também pensando um pouco da ideia da crítica da Geografia relacionada a isso. Mas pensar também nessa mistura toda tão específica do que ela proporciona eu acho um negócio muito fantástico. E não só pelo aspecto cultural, acho que é muito mais do que isso porque forma um sujeito diferenciado, esse sujeito da fronteira que cresceu em torno de um contexto peleado, muita briga...então 'ah o pessoal da fronteira é meio briguento'. Eu acho que até é briguento sim mas também têm os seus códigos de fraternidade que são muito importantes. Pra mim a fronteira sempre foi um pedaço de casa. Estar de um lado, estar de outro...eu me senti um pouco privilegiada com isso"

\section{MILITANTE DA FAG 1}

"...de repente veio a coisa do encontro. Nós não temos essa barreira aqui. E eu acho muito massa. E lá, e ao natural, já sai tentando falar em espanhol (...) Como que pode um espaço, não é uma fronteira, é um espaço em que aqui eu me comporto desse jeito e a partir daqui eu me comporto de outro? Como é que se estabeleceu esse limite? Como é que isso acontece? Que decreto é esse que consegue repartir? Só que ali tu consegue ver uma mistura, não é tão 'aqui acaba, ali começa'. Acho que por uma concepção de ver essas proximidades, essa necessidade de encontrar".

\section{MILITANTE DA FAG 2}

"Son límites administrativos que se ponen a repartir un pedazo de tierra, un tanto institucionalizados, naturalizadas, cerca de la noción de límite como herramienta disciplinadora de las mientes"

\section{MILITANTE DA FAU}


"Sempre notei que existem muitos pontos em comum entre as populações das fronteiras, e em caso de latinoamerica as fronteiras são muito mais virtuais que na Europa, são inventos dos Estados locais, das classes dominantes locais, são muito jovens as fronteiras cá em latinoamerica"

\section{MILITANTE DA FAR}

Fonte: trabalho de campo.

virtualidade das bordas dos Estados territoriais ("Sempre notei que existem muitos pontos em comum entre as populações das fronteiras, e em caso de latinoamerica as fronteiras [...] são inventos dos Estados locais"). Da fronteira como um referencial espacial temos a abordagem da identidade sócio-espacial (Caixa 2). 0 universo valorativo gaucho é visto pelos ativistas das Federações Anarquistas como algo que pode ser reivindicado em uma perspectiva libertária. No Rio Grande do Sul o problema da apropriação conservadora da identidade remete ao movimento tradicionalista, e os ativistas buscam separar as referências da cultura popular da massificação e elitização dos símbolos gauchos ("Eu tenho a crítica a essa cultura do tradicionalismo, porque eu acho que formaram, forjaram a ideia de um gaúcho fictício, digamos assim. Essa coisa de vestimenta, a gente vê isso acontecer em 20 de setembro, se fantasiam de gaúcho, esse tipo de coisa"). O gaúcho reverberado pelos meios de comunicação de massas não é aquele trabalhador pobre do campo, mas sim do estancieiro, do latifundiário.

A força da mitificação conservadora/elitista no Rio Grande do Sul é tamanha que em determinado momento o indivíduo se acha em conflito ao nutrir sentimentos por um universo de valores por vezes confuso entre elementos populares e elementos de massa. Já no Uruguai e na Argentina o gaucho é visto pelos ativistas primordialmente como uma figura rebelde pertencente à classe trabalhadora rural, a despeito da apropriação conservadora da identidade realizada pelo nacionalismo ao longo do século XX ("creo que a nivel popular se honra la palabra gaucho"). Valores como rebeldia, resistência às imposições "civilizadoras" e ao cercamento da pampa e uma imagem muito próxima à pobreza do campo são constantes nas falas dos platinos; porém, atualmente, faz-se ressalvas à reivindicação do gaucho pela ideologização nacionalista de sua figura ("Mas a identidade gaucha hoje tem relação direta com uma

Caixa 2 - Universo valorativo gaucho segundo ativistas das Federações Anarquistas.

UNIVERSO VALORATIVO GAUCHO
"Eu tenho a crítica a essa cultura do tradicionalismo, porque eu acho que formaram, forjaram a
ideia de um gaúcho fictício, digamos assim. Essa coisa de vestimenta, a gente vê isso
acontecer em 20 de setembro, se fantasiam de gaúcho, esse tipo de coisa. Então tem toda
uma construção social em torno do que é ser gaúcho, que ta vendendo os "Tche Music" da
vida, que ta vendendo altas coisas, e com isso eu não corroboro nem um pouquinho. Mas eu
acho que ser um gaúcho está na constituição social desse sujeito misturado com índio,
misturado com negro, misturado com essas peleias que foram marcando a história desse
povo todo. Eu não acho que é ruim a gente se reivindicar gaúcho. O que é ruim é aquilo que
construíram em torno dessa ideia do tradicionalismo, do CTG, dos fazendeiros, donos de
terra...sou bem contra".
MILITANTE DA FAG 1
"É uma mescla de sentimentos, confronto, repulsa na época em que se vivia e ter afeto com o
lugar quando tu volta. Uma sensação curiosa, tu fica com dois corações, mas também de se
perguntar. (...)Estou fazendo um curso de dança de salão de fandango - olha só onde eu me
meti. Mas desprezo a cultura tradicionalista, desprezo assim porque é uma estupidez, é
manutenção de uma cultura conservadora, machista, homofóbica, opressora, exploradora.
Todos os conceitos, os valores talvez que reúnem o capitalismo estão ali. Só que a coisa tu
voltar no passado e como que tu distingue a vida do campeiro, que vive no campo mesmo, e a


cultura do tradicionalismo? O gaúcho que trabalha lá, que eu conheci, que eu vi de perto, que eu ajudei, que eu conversei no trabalho, não é arrogante como o patrão, o fazendeiro. Mal fala. Aqui o gaúcho é aquele gritão, que se impõe. Eu me lembro que tinha um peão lá no tio Juvelino, ele mal falava, ele só concordava, atendia, era de uma educação absurda. E aí o tradicionalismo prega esse 'ah eu sou do tempo...' (...) É legal a bailanta, o ritmo pra dançar, a gente têm se divertido nesse negócio. Eu volto a essa atmosfera mesmo repudiando os valores que o tradicionalismo produz. É uma estupidez. Mas é legal várias coisas. Tanto é que os ritmos que é da mescla, o chamamé, a milonga, esses aí me tocam mais do que aqueles que são de influência...tem a polca, o xote, que são mais europeus. A milonga é uma palavra africana. E o chamamé é do norte da Argentina, Corrientes".

\section{MILITANTE DA FAG 2}

"...creo que a nivel popular se honra la palabra gaucho. 'Hacer una gauchada' es hacer un favor de buena fe, de voluntad, no porque lo piden, no porque otra persona lo está debiendo. Creo que es una homenaje a la idea y la representación de lo que significa gaucho (...)El gaucho como formación, como sujeto si se quieres (...) se forma con las vertientes del lo criollo, de los indios, de los negros - de pueblos esclavos, mejor dicho - y daí se hace el sujeto de resistencia a todo el orden civilizatoria que se hacía luego, el orden de disciplinamiento de los cuerpos en el campo en general y a través de la obligatoriedad de la escuela pública y del alambramiento de los campos, cosas que en buena medida buscaran destrozar la cultura del gaucho. La cultura del gaucho era una cultura retobada (...)el indio comienza a vincularse en el rodeo animal con el gaucho para trabajar en un campo que no estaba alambrado, que el gado era cimarrón, andaba suelto por el campo (...)existen rastros de manejo ganadle y de identidades culturales de producción en ganadería con el conocimiento mesclado de la relación del gaucho con el indio".

\section{MILITANTE DA FAU}

"Aqui Uruguai, Rio Grande do Sul e a pampa húmeda argentina tiveram as mesmas formas de produção, de trabalho no campo, as mismas culturas do trabalho, a mesma troca da produção...en ese sentido sim, há identidade, inclusive com el gaucho, a figura da identidade agrária, da identidade cultural do campo (...)Originariamente o gaucho não era um camponês, era um trabalhador que trabalhava para alguns senhores ou não. No século XIX e no princípio do século XX alguns colonos vindos da Europa, Itália, Espanha, França e outros países, haviam vindo para trabalhar a terra com promessas dos governos locais de prosperidade, de melhor vida do que na Europa. Então alguns desses colonos assimilaram certos costumes da população gaucha local. Mas a identidade gaucha hoje tem relação direta com uma identidade inventada pela historiografia oficial dos fundadores do Estado Nacional, dos fundadores da pátria, de ideologia nacionalista, tradição. (...) Mas essa concepção, essa identidade gaucha o Estado centralista que ganhou as brigas internas impuso outra identidade gaucha que é muito superficial, que tem muito que ver com a pessoa que tem vacas, tem campo, se veste de uma maneira muito particular, o dono dos meios de produção digamos assim".

\section{MILITANTE DA FAR}


identidade inventada pela historiografia oficial dos fundadores do Estado Nacional, dos fundadores da pátria, de ideologia nacionalista, tradição").

Ao serem questionados a respeito das pontes possíveis entre a identidade soócio-espacial gaucha, o anarquismo e as lutas sociais (Caixa 3), os ativistas dos três países convergem no destaque das características de mestiçagem, rebeldia e insubordinação do gaucho e na importância de se debater a dimensão simbólicocultural das lutas sociais. A relevância de se resgatar à luz da história esse gaucho desde abajo é ponto de partida para a identificação das pontes existentes e para a construção de novas pontes ("Porque a história do gaúcho infelizmente ainda é contada pelos de cima, pela vitória dos de cima, pelos fazendeiros, pelos CTGs. Contar a história a partir do de baixo, desse sujeito malquisto, pé-sujo mesmo, grosso, a gente não vê com muita facilidade"). Os valores e as visões de mundo compartilhados por homens e mulheres trabalhadores rurais ao longo dos tempos precisam ser destacados e afirmados em seu aspecto "ingovernável" ("Acho que tem um encontro cultural aí e elementos de comportamento que nos servem como anarquistas como sujeto ingobernable, que não vai aceitar imposição. 0 gaúcho é fruto do estupro, e o guasca que vivia trabalhando sem patrão e vivia do contrabando, e às vezes do roubo e do assassinato [...] o universo da luta simbólica é fundamental. Tu criar a tua aldeia e essa aldeia gritar pra fora dos muros") e de busca de autonomia contra a burocratização e a oficialização heterônoma da vida ("Acho que a cultura gauchesca ou gaucha pode se aproximar de algo que não tem tutela, que não tem certificado. Isso é próximo do anarquismo. 0 que não é uma criação estatal, um decreto, uma medida provisória, um documento autorizado por uma pessoa. Acho que isso é interessante, a quebra da burocracia entre as pessoas. São similaridades que acho que dá pra aproximar esses dois universos, da política anarquista e da cultura nativista, criolla, mestiça"). Os vínculos entre a identidade sócio-espacial gaucha e o anarquismo se estreitam no rechaço à ordem estabelecida, à autoridade dominante e, em uma perspectiva latino-americana, anticolonialista/descolonial ("Hay en eso, claro, un vínculo local, un rechazo de un orden que ha sido impuso, una negación de la autoridad disciplinadora y esclavista, una idea si se quiera anticolonialista"). Apesar da falta

Caixa 3 - Relações entre a identidade sócio-espacial gaucha, o anarquismo e as lutas sociais segundo ativistas das Federações Anarquistas.

RELAÇÃO IDENTIDADE GAUCHA - ANARQUISMO E LUTAS SOCIAIS

"...acho que não só o gaúcho mas tantos outros povos também tem essa marca da peleia cotidiana, talvez um pouco do que constitui esse sujeito brasileiro que não desiste nunca, ou do gaúcho de 'não podemos se entregar pros homem, e não tá morto quem peleia', é mais ou menos por aí a coisa. (...) Se tu fores pegar por exemplo a própria declaração de princípios da organização ela vai trazer elementos do que é o sujeito gaúcho, vai separar o joio do trigo, digamos assim. Porque a história do gaúcho infelizmente ainda é contada pelos de cima, pela vitória dos de cima, pelos fazendeiros, pelos CTGs. Contar a história a partir do de baixo, desse sujeito mal quisto, pé sujo mesmo, grosso, a gente não vê com muita facilidade. Mas ele é fundamental, eu acho super importante (...)O que constitui esse povo gaúcho? O que leva esse traçado de elementos culturais que vai desde aquilo que se compartiu e se comparte ainda da cultura indígena e negra que é muito forte no nosso território pra dizer "ah, aqui nós temos uma cultura gaúcha"? Tem muita coisa importante pra tratar quando a gente ta falando de cultura, ideologia, esses elementos do imaginário social. Eu acho que de certa forma a gente se esforça bastante pra que isso não seja algo à parte, ao contrário, seja constitutivo daquilo que a gente quer estudar. E essas esferas se cruzam, tanto a esfera econômica, jurídica, política, ideológica, social...elas estão em constante interdependência. Em alguns momentos uma vai ser mais determinante que a outra. Não temos como negar que hoje a gente vive em um sistema capitalista, onde o dinheiro é determinante pra muitas coisas, mas tem outras relações que leva isso a ser determinante. A grande ferramenta de dominação do meio de comunicação, por exemplo...por que ela é tão poderosa? O poder simbólico assim... Mas que bom, a gente quer tratar dessa cultura como algo importante pra constituir a organização política, os elementos de debate". 
"Acho que tem um encontro cultural aí e elementos de comportamento que nos servem como anarquistas como sujeto ingobernable que não vai aceitar imposição. O gaúcho é fruto do estupro, e o guasca que vivia trabalhando sem patrão e vivia do contrabando, e às vezes do roubo e do assassinato (...) Eu não tenho esse domínio da informação histórica mas eu trago essa coisa de colocar essa sensação de que parece que isto é uma luta importante. Até por ser das Artes, o universo da luta simbólica é fundamental. Tu criar a tua aldeia e essa aldeia gritar pra fora dos muros. Então eu acho que isso dá pra aproximar com a coisa do sujeito que não ta preso a uma demanda política, sabe (...) Eu não dependo dum limite político pra me solidarizar ou não com um sujeito humano que ta ali do outro lado da fronteira que até falar parecido comigo fala (...)Acho que a cultura gauchesca ou gaucha pode se aproximar de algo que não tem tutela, que não tem certificado. Isso é próximo do anarquismo. $O$ que não é uma criação estatal, um decreto, uma medida provisória, um documento autorizado por uma pessoa. Acho que isso é interessante, a quebra da burocracia entre as pessoas. São similaridades que acho que dá pra aproximar esses dois universos, da política anarquista e da cultura nativista, criolla, mestiça (...)Aí eu penso 'anarquista gaúcho': pra cá não me afirmo, mas pra fora sim, a identidade gaúcha é ilegal. A que eu resgato, a que eu levo lá na bandeira da organização que eu to vinculado, ela resgata um outro sujeito que não é o que tá no Galpão Crioulo, é outro. É um muito mais rasteiro. Fico naquele conflito nostálgico e de origem. $\mathrm{Na}$ origem tu combate e no externo ou em rememorar tu resgata aquilo que te conforta. Talvez pela coisa urbana, eu gosto da cidade, de ter me misturado com a coisa do grafite, da pichação, eu gosto dessa selva, é interessante desbravar ela".

MILITANTE DA FAG 2

"Algunas cosas, seguramente algunos vínculos deben existir (...)hay muchos puntos de contacto con la poética anarquista y libertaria como los que están reflejados en las canciones de Carlos Molina y también en el arte de Chito de Mello a Rivera, es un artista de primera categoría cuanto a calidad de su canto y de su arte en la frontera de Uruguay con Brasil. Hay en eso, claro, un vínculo local, un rechazo de un orden que ha sido impuso, una negación de la autoridad disciplinadora y esclavista, una idea si se quiera anti-colonialista, porque en todos los pueblos de América los "gauchos" de cada lugar, los "gauchos" de Venezuela, los "gauchos" de Colombia, lucharan contra los españoles. Entonces vínculos con el anarquismo...yo creo que sí, de hecho. Las luchas obreras de Tucumán de 1920 liderados por la FORA anarcosindicalista en Argentina tiene algo que ver con la resistencia de los pueblos originarios, muy cercano al chaco, donde hay el gaucho, tiene El Gauchito Gil, un montón de gauchos en Paraná, en Corrientes. Otra cuestión es que sí, cuando hablamos del gaucho hablamos del gaucho sin pensar en las barreras concretas de Argentina-Brasil o de Argentina-Uruguay o de UruguayBrasil (...)yo soy anarquista y reivindico a Martín Aquino, El Último Matrero Uruguayo, lo reivindico por matrero, por rebelde, por su astucia...yo pongo eso con rudimentario conocimiento pero debe existir mucho más que no se conoce de rebeldía en el campo...Y CHARLAN SOBRE ESO EN LA FAU? Sí, por la idea que se tiene del gaucho, una idea rebelde, es un asunto un tanto común".

\section{MILITANTE DA FAU}

"Existiu no século XIX até o meio do século XX uma identidade gaucha vinculada às montoneras federalistas, federalismo dos povos das províncias, um federalismo de baixo, um tipo de federalismo, como dizer, mais igualitário. A identidade gaucha tinha essa relação com as montoneras gauchas, chamadas assim: montoneras gauchas. Ejemplo disso é a experiência histórica das montoneras das províncias de La Rioja, Catamarca, Santa Fe, Entre Ríos, que tinham figuras como Chacho Peñaloza, Felipe Varela, Facundo Quiroga, Pancho Ramirez, López Jordan, Estanislao López... Alguns deles tinham muita identidade com as 
pessoas do campo, com os gauchos (...) No meio do século XX um escritor anarquista, Ezequiel Martinez Estrada, publicou um livro com a reinterpretação do Martín Fierro e uma análise das questões que estavam nas entrelinhas da análise de Hernández, é muito interessante esse material. Ele é um intelectual que vem do anarquismo. E também existiu uma confluência da cultura gaucha tradicional e os trabalhadores rurais que vieram da Europa, que formou uma nova identidade, inclusive com o anarquismo. Tiveram muita relação com alguns processos e hechos históricos que aconteceram por ejemplo na Patagônia rebelde. Os trabalhadores rurais que foram assassinados pelo Estado tinham muita identificação com os gauchos. Mira a película La Patagonia Rebelde e vê o personagem Facón Grande que era um gaucho nascido em Entre Ríos - ele existiu de verdade. Muitos migraram do centro do país e da pampa húmeda, e também de Chile, para a Patagônia (...) Também teve relação com os bandidos rurais. Teve muita identificação a identidade anarquista com o ladrão gaucho. Houve muitos ladrões que foram influenciados pela ideologia anarquista, como Vairoletto, Mate Cocido e outros ladrões do campo, expropriadores. Acá se llamaran historicamente cuatreros, porque roubavam ganados. Também anarquistas escreveram algumas coisas em referência ao gaucho que quedó desempregado no princípio da industrialização argentina. Com o gaucho desempregado alguns anarquistas se identificaram, e um escritor produziu La Carta Gaucha que teve esse ponto de contato com a identidade gaucha".

\section{MILITANTE DA FAR}

Fonte: Trabalho de campo.

de menções mais explícitas nos documentos das Federações em geral, o universo valorativo gaucho é bem recebido e comentado pelos anarquistas do Prata ("por la idea que se tiene del gaucho, una idea rebelde, es un asunto un tanto común").

Vejamos agora a experiência das relações entre as três Federações em questão (Caixa 4). A mais antiga delas, FAU, fomentou a fundação das outras duas organizações (FAG em 1995 e FAR em 2008, mas apenas desde 2014 com esse nome). Apesar de menções a uma cultura política que aproxima Rio Grande do Sul, Uruguai e Argentina ("Tem uma cultura política que facilita as coisas com o Uruguai e com a Argentina. Tem uma proximidade muito grande, aquelas coisas que depois a gente foi transformando ou adaptando"), o âmago das interações transnacionais está no compartilhamento de uma forma organizacional e da estratégia especifista; assim, na fala dos ativistas, nota-se a importância dos estudos e das trocas teóricas e de formação política - materiais de estudo e de opinião política - entre as organizações.

Apesar de a FAG filiar-se à Coordenação Anarquista Brasileira, o contato com os hermanos argentinos e uruguaios é maior ("Nós temos um terreno de articulação muito fértil entre Uruguai, Argentina, principalmente pela questão territorial, a proximidade. As organizações aqui do Sul têm mais contato com Uruguai e com Argentina do que as organizações mais pra cima"). As relações umbilicais FAU-FAG expressam-se, então, em dois níveis de articulação transnacional: o nível ideológico, que envolve estudos teóricos e formação; e o político-social, com opiniões compartilhadas, análises de conjuntura, e solidariedade além-fronteiras estatais quando uma das organizações ou seus ativistas encontram-se ameaçados pelas forças repressoras do Estado.

Os ativistas da FAG não poupam palavras para expressar a importância do suporte da FAU ao longo de seus mais de 20 anos de existência, destacando que as organizações se encontram em momentos distintos dada a grande diferença de "idade" entre elas ("É uma organização extremamente importante pra nós, então os vínculos que a gente mantém são de muita fraternidade, de muita responsabilidade de uma organização com a outra. A gente se visita regularmente, a gente compartilha nossos materiais de estudo, nossos materiais de opinião política, a gente faz reuniões em conjunto. Somos praticamente a mesma organização, só que em territórios diferentes. Claro, eles com uma bagagem diferenciada da nossa. A FAU tem um diferencial com relação a nós porque ela cultiva os velhinhos ainda, então, tem vários militantes com oitenta e poucos anos e uma militância mais nova. Os nossos militantes mais velhos têm uns 37, 38 anos. Não se compara"). A formação política é compartilhada e em cada lugar ganha novos contornos 
dadas as diferentes demandas e realidades concretas com que os ativistas se deparam ("No nível político, a formação é um dos elementos importantes porque uma das tarefas de qualquer organização política é sempre atualizar a formação e pensar desde onde tá atuando, porque nenhuma organização tem capacidade de ser efetiva numa conjuntura política se não estudar bem a conjuntura política que está vivendo... o sujeito social que tá trabalhando, qual é a constituição desse país, quais são as culturas com as quais estamos mexendo, o que levou essas culturas a serem formadas... São aspectos importantes de câmbio entre essas organizações [...] Esse intercâmbio da formação política e ideológica é uma das coisas fundamentais"), como, por exemplo, o apoio da FAG à luta dos quilombolas no Rio Grande do Sul e o compartilhamento dessa experiência com as outras Federações (La naturaleza de las relacionas con la FAG son de una propuesta específica y concreta de una organización anarquista, que en varios momentos fue cobrando diferentes formas y propuestas para llegar a la FAG, donde yo tengo el placer de conocer a varios compañeros, compañeros queridísimos que fueron con seguridad y con contundencia ideológica armar una propuesta seria, una propuesta que no era una aventura ni una ocurrencia elaborada para el momento si no formar una organización que dé respuestas a las injusticias del momento y que tenga la capacidad de producir alternativas y colocarse a la altura de las circunstancias que está viviendo el pueblo trabajador, trabajadores y trabajadoras, desocupados y desocupadas, los pobladores y pobladoras quilombolas de Porto Alegre y del estado de Rio Grande do Sul, y a su vez extender eso a otra propuesta reconociendo y dándole valor a otras propuestas que tenemos en este continente llamado Brasil)

As trocas ideológicas e teóricas são tamanhas que tocam os ativistas em sua identidade, como se uma identidade comum emergisse das relações transnacionais e assegurasse a existência e a reprodução das Federações ("Com a FAU já é uma troca de construção teórica (...) é uma questão identitária mesmo, de tu se sentir continuador e partícipe daquela ação, daquele movimento. Isso eu acho que é um patrimônio que a gente conseguiu ter com os companheiros da FAU. O outro é importar um modelo de organização, que eu acho que foi a fortaleza da FAG durante esses anos, que é estarmos federados, nucleados. Organização de assembleia privilegia carisma - quem fala mais alto, quem fala bonito, quem consegue elaborar... e a FAU nos ensinou que tem que sermos nucleados, grupos pequenos, onde todos possam participar, onde eu não me constranjo em defender algo, garantir a voz do companheiro. Fazer isso acho que foi o que garantiu a existência da FAG").

Notou-se, no entanto, que as interações FAU-FAG, por exemplo, são de intensidade distinta das interações FAU-FAR ou FAG-FAR. A relação entre brasileiros e uruguaios é mais intensa e duradoura, enquanto as relações entre brasileiros e argentinos é menos intensa devido, entre outras coisas, ao menor tempo de existência da FAR e também de diversas organizações anarquistas argentinas possuírem caráter efêmero e sectário, segundo os ativistas abordados ("A relação com os uruguaios é mais regular, mais intensa. Com o Uruguai atravessou aquela coisa orgânica e virou um grau de afetividade extremamente grande, então isso ajuda também a fortalecer. Sempre se teve contato com os argentinos, mas os argentinos têm uma característica de, não sei se é cultural ou da personalidade, eles racham, acabaram com organizações muito sistematicamente durante esses anos. Agora a gente de novo tem relação com uma organização que é a FAR, de Rosário, com estabilidade. Uma relação que se assentou. Inclusive tem antigos militantes anarquistas de outras organizações que estão ali, e se teve muita relação com companheiros argentinos, mas sempre teve isso - eles se dissolviam com muita facilidade. Então quebrava a continuidade de contato").

Atenta o militante da FAU para a natureza distinta de tais relações ("Es otro relacionamiento, importante, pero con una raíz y una naturaleza distinta de la FAG, por el tiempo, porque tienen otro tiempo de lectura, por el estilo y las tradiciones concretas, formación social distinta. De Rosario lo conocíamos algunas experiencias de colectivos anteriores y que tuvieran vínculo con FAU, vínculo riquísimo (...) los compañeros nos anuncian que van armar una propuesta de Federación Anarquista a Rosario y nos invitan a participar, y ahí comienza otro relacionamiento") e para o risco de se enxergar uma inexistente homogeneidade de interações ("...tienen etapas, historia e trayectorias distintas que la de la FAG, y por eso que eso de hablar de las relaciones FAU-FAG-FAR me parece una pseudoigualdad dónde no lo existe. $Y$ no quiero con eso nivelar o hacer cosas como un segundo, tercer o cuarto nivel, si no simplemente ser justo, sin quitar el merito y sí rindiéndole honor"). Em todo caso, o Encontro Latino-americano de Organizações Populares Autônomas (ELAOPA), realizado a cada 2 anos, é um importante reflexo da construção desse ativismo transnacional. 
Caixa 4 - Ativismo transnacional FAG-FAU-FAR segundo ativistas das Federações Anarquistas.

\section{ATIVISMO TRANSNACIONAL FAG-FAU-FAR}

"Tem uma cultura política que facilita as coisas com o Uruguai e com a Argentina. Tem uma proximidade muito grande, aquelas coisas que depois a gente foi transformando ou adaptando (...) A formação da FAG tem um peso muito grande da FAU, é uma organização co-fundadora da nossa - a FAU já tem mais de 60 anos, a FAG mais de 20. É uma organização extremamente importante pra nós, então os vínculos que a gente mantém são de muita fraternidade, de muita responsabilidade de uma organização com a outra. A gente se visita regularmente, a gente compartilha nossos materiais de estudo, nossos materiais de opinião política, a gente faz reuniões em conjunto. Somos praticamente a mesma organização só que em territórios diferentes. Claro, eles com uma bagagem diferenciada da nossa. A FAU tem um diferencial com relação a nós porque ela cultiva os velhinhos ainda, então tem vários militantes com oitenta e poucos anos e uma militância mais nova. Os nossos militantes mais velhos têm uns 37, 38 anos. Não se compara. Com a Argentina também é uma relação super fraterna e boa politicamente com várias organizações, principalmente com Rosário, onde foi fundada a Federação Anarquista de Rosário. É uma organização também irmã por conta da linha do especifismo. Tem outras organizações que são parceiras nossa na Argentina também, super solidárias, mas não necessariamente especifista. Nós temos um terreno de articulação muito fértil entre Uruguai, Argentina, principalmente pela questão territorial, a proximidade. As organizações aqui do sul têm mais contato com Uruguai e com Argentina do que as organizações mais pra cima. Nós fazemos parte da CAB, Coordenação Anarquista Brasileira (...)No nível político, a formação é um dos elementos importantes porque uma das tarefas de qualquer organização política é sempre atualizar a formação e pensar desde onde ta atuando, porque nenhuma organização tem capacidade de ser efetiva numa conjuntura política se não estudar bem a conjuntura política que está vivendo...o sujeito social que ta trabalhando, qual é a constituição desse país, quais são as culturas com as quais estamos mexendo, o que levou essas culturas a serem formadas... São aspectos importantes de câmbio entre essas organizações. Então, a formação política e ideológica, no âmbito político, dos elementos mais do núcleo duro da organização do nosso marco teórico que demanda trabalho, demanda compromisso e militância. Esse intercâmbio da formação política e ideológica é uma das coisas fundamentais. No campo social, uma das ferramentas de articulação nossa e entre essas organizações é o ELAOPA que a gente constrói a cada dois anos. O último foi em Montevidéu, lá no bairro Cerro, reuniu delegações de diferentes países, e é um encontro bom pra marcar solidariedade com diferentes setores, marcar linha de atuação sindical, estudantil, comunitário".

\section{MILITANTE DA FAG 1}

"...essa foi uma liga que foi pra além, e aí é o sentido de tu te sentir um continuador. Coloca o elemento político-histórico do que se fez, da importância e da ousadia que eles tiveram no país deles, como fizeram. A questão do estudo, do pau-pra-toda-obra. Um pouco nos atrapalhou isso, porque a gente exigia de uma forma da gente, que tinha que ser pau-ferro, é assim, é assim, senão não. Não tinha essa coisa contrarrevolucionária marxistóide, a gente não era apegado a uma determinada terminologia que condenava o outro, mas dum comportamento que imprimia uma cultura meio familiar, tamo junto e fechado. Quem não ta nessa vamo pro pau. Tinha um certo sectarismo. Muita agressividade ao se colocar em relação a outras forças políticas. Em compensação deu essa identidade muito forte inter-fronteiras, gaudéria e latina (...)A relação com os uruguaios é mais regular, mais intensa. Com o Uruguai atravessou aquela coisa orgânica e virou um grau de afetividade extremamente grande, então isso ajuda também a fortalecer. Sempre se teve contato com os argentinos, mas os argentinos têm uma 
característica de, não sei se é cultural ou da personalidade, eles racham, acabaram com organizações muito sistematicamente durante esses anos. Agora a gente de novo tem relação com uma organização que é a FAR, de Rosário, com estabilidade. Uma relação que se assentou. Inclusive tem antigos militantes anarquistas de outras organizações que estão ali, e se teve muita relação com companheiros argentinos, mas sempre teve isso - eles se dissolviam com muita facilidade. Então quebrava a continuidade de contato (...)Se desenvolveu principalmente nos níveis sociais dentro do ELAOPA. A gente conseguia coordenar algumas datas de ação em conjunto, conseguia tirar vários momentos de intervenção coordenada em algumas fechas, e pra além disso em algum momento a gente sentava com as organizações específicas e discutia, fazia um balanço, uma análise conjuntural, como estava a vida orgânica, trocava umas figurinhas, sempre no sentido de troca. Com a FAU já é uma troca de construção teórica (...)é uma questão identitária mesmo, de tu se sentir continuador e partícipe daquela ação, daquele movimento. Isso eu acho que é um patrimônio que a gente conseguiu ter com os companheiros da FAU. O outro é importar um modelo de organização, que eu acho que foi a fortaleza da FAG durante esses anos, que é estarmos federados, nucleados. Organização de assembleia privilegia carisma - quem fala mais alto, quem fala bonito, quem consegue elaborar... e a FAU nos ensinou que tem que sermos nucleados, grupos pequenos, onde todos possam participar, onde eu não me constranjo em defender algo, garantir a voz do companheiro. Fazer isso acho que foi o que garantiu a existência da $F A G$, passar esses anos, superar os problemas que qualquer organização vai ter, de combater a coisa da vaidade, de combater o status "ah aquele ali escreve e esse aqui imprime cartaz, e aquele ali milita no bairro e aquele puxa carrinho de catador". É combater, fazer um franco enfrentamento a essas cristalizações. E isso até hoje existe na FAU, eles combatem isso (...)a epistemologia do nosso anarquismo, esse conhecimento que a gente vem desenvolvendo. Colaboração teórica, leitura de realidade. $\mathrm{E}$ isso dá em pessoas que nem são anarquistas a contribuição que elas podem ter pra elaborar a teoria política. E isso pra mim a cultura do Uruguai me ensinou muito: a busca do estudo permanente, garantir o estudo que é tarefa do educador. Tem que ler o resto da vida, tem que se preparar".

\section{MILITANTE DA FAG 2}

"Siempre tenemos en la FAU un relacionamiento que se quiere ser mundial, con organizaciones de todos los cantos. Los vínculos son esfuerzos de interpretar al máximo lo que se suceden en los lugares donde hay propuestas rebeldes que no se reivindican anarquistas pero son propuestas de emancipación, de lucha de clases, ojalá son anarquistas no de la misma manera nuestra pero sí ramos de un árbol, y eso te obliga alegremente a llamarlos de compañeros porque efectivamente son compañeros. La naturaleza de las relacionas con la FAG son de una propuesta específica y concreta de una organización anarquista, que en varios momentos fue cobrando diferentes formas y propuestas para llegar a la FAG, donde yo tengo el placer de conocer a varios compañeros, compañeros queridísimos que fueron con seguridad y con contundencia ideológica armar una propuesta seria, una propuesta que no era una aventura ni una ocurrencia elaborada para el momento si no formar una organización que dé respuestas a las injusticias del momento y que tenga la capacidad de producir alternativas y colocarse a la altura de las circunstancias que está viviendo el pueblo trabajador, trabajadores y trabajadoras, desocupados y desocupadas, los pobladores y pobladoras quilombolas de Porto Alegre y del estado de Rio Grande do Sul, y a su vez extender eso a otra propuesta reconociendo y dándole valor a otras propuestas que tenemos en este continente llamado Brasil (...)Hay todo un tiempo y muchas vivencias que han producido una interacción muy grande con la FAG. Van para 25 años. Seguramente se están incorporando a la FAG compañeros y compañeras que no tienen 25 años, que tienen menos, qué importancia esta otra generación! Eso es una cosa que debería ser anotada, las relaciones FAU-FAG, que propuesta, lo que acabó, lo que se llevó adelante... Acá nosotros sabríamos que pasaba algo 
con FAG y en 15 minutos estábamos en Brasil, sin problema. Con la FAG se arma una idea que luego son de las organizaciones sociales, y luego se construyó la propuesta de ELAOPA, primero una instancia dentro del Forum Social Mundial de Porto Alegre (...)Y así surge el vinculo con la Columna Libertaria Joaquín Penina [Rosario]. Es otro relacionamiento, importante, pero con una raíz y una naturaleza distinta de la FAG, por el tiempo, porque tienen otro tiempo de lectura, por el estilo y las tradiciones concretas, formación social distinta. De Rosario lo conocíamos algunas experiencias de colectivos anteriores y que tuvieran vínculo con FAU, vínculo riquísimo (...)los compañeros nos anuncian que van armar una propuesta de Federación Anarquista a Rosario y nos invitan a participar, y ahí comienza otro relacionamiento. Bueno, tienen etapas, historia e trayectorias distintas que la de la FAG, y por eso que eso de hablar de las relaciones FAU-FAG-FAR me parece una pseudoigualdad dónde no lo existe. $Y$ no quiero con eso nivelar o hacer cosas como un segundo, tercero o cuarto nivel, si no simplemente ser justo, sin quitar el merito y sí rindiéndole honor".

\section{MILITANTE DA FAU}

"Em princípio tem muita relação com o planejamento do anarquismo especifista. 0 anarquismo especifista tem a particularidade de que se fortalece através do crescimento dos diferentes lugares, através do nascimentos das organizações especifistas, das federações, e se debilita se não existem outras organizações em outros lugares do cone sul. 0 desenvolvimento do anarquismo especifista tem perta relação com o planejamento da FAU, da FAG, das outras organizações da CAB, e sua influência em outras organizações na Argentina e em outros países como Chile, Paraguai, Colômbia, Peru, está intimamente ligado com o desenvolvimento em outros países. As travas, as dificuldades, tem que ver muito com as barreiras culturais dos idiomas e com os diferentes níveis do desenvolvimento das organizações, diferentes momentos, diferentes anos de vida. A FAR tem 10 anos mas constituída como FAR, com esse nome, tem quase 3 anos. Mas é importante falar que a estratégia do especifismo tem relação direta com o desenvolvimento de organizações em diferentes países. Não existe centralidade da estratégia. Está muito ligada ao federalismo (...)a estratégia do especifismo que tem por um lado os encontros como ELAOPA, os demais encontros das organizações anarquistas do Cone Sul. Tem muito que ver com estar periodicamente em encontros - a estratégia do especifismo se fortalece com os encontros bilaterales ou multilaterales. Ambos os encontros e a multilateralidade. Acho que daqui pro futuro as lutas nas diferentes regiões vão ter que contar com uma solidariedade próxima entre as organizações. Você tem que ver que a FAG com Rosario tem pouco mais de mil quilômetros. Também tem uns 800 ou 900 quilômetros entre Porto Alegre e Montevideo. Também entre Montevideo e Rosario tem 600 quilômetros. Hay que aproveitar a cercanía da região pra edificar e construir esse anarquismo na região. Dentro do Cone Sul é perto para desenvolver o anarquismo, e isto estamos fazendo agora".

MILITANTE DA FAR

Fonte: Trabalho de campo.

A solidariedade transnacional se faz presente em momentos de ameaça, perseguição e opressão por parte do Estado. Exemplo disso são os momentos em que a FAG foi ameaçada e invadida pelas polícias civil e militar do Rio Grande do Sul, a contar quatro vezes desde $2009^{8}$. A última investida contra a Federação Anarquista Gaúcha ocorreu em outubro de 2017, quando foi

¿Ver a respeito o artigo "Quarta investida sobre a FAG em menos de 10 anos". Disponível em: <https://federacaoanarquistagaucha.wordpress.com/2017/10/26/ quarta-investida-repressiva-sobre-a-fag-em-menos-de-10-anos/>. Acessado em: 28 de outubro de 2017 deflagrada uma investigação criminal contra mais de 30 pessoas denominadas pela polícia como "anarquistas" e acusadas de promover ações terroristas em Porto Alegre, numa tentativa de enquadrar o anarquismo na Lei Antiterrorismo. A batida policial se deu na sede de outra organização, porém oficialmente o mandado de busca e apreensão continha o nome FAG. Nesse contexto, diversas organizações (libertárias ou não) solidarizaramse, dentre elas a FAR, como mostra a Figura 1. 
Figura 1 - Comunicado de solidariedade da FAR com a FAG, outubro de 2017.

\section{Comunicado de Solidaridad con la FAG}

La Federación Anarquista de Rosario expresa su profunda solidaridad con nuestros/as hermanos/as de la Federación Anarquista Gaucha que están sufriendo una brutal persecución política, una vez más, por el Estado Brasilero y Riograndense.

La avanzada represiva de los de arriba es inaceptable. El problema de la pobreza, la desocupación, la flexibilización laboral y la precarización en Brasil NUNCA se van a solucionar desde la persecución a los/as que luchan. Siempre desde la creatividad y lucha de las organizaciones populares.

Exigimos el cese de esta absurda y ridícula persecución. Nuestros/as compañeros gaúchos no son los responsables de la desigualdad y la pobreza riograndense, sino parte de la solución y la esperanza revolucionaria.

Compañeros gaúchos nos ponemos a plena disposición para lo que necesiten en este difícil momento provocado por un puñado de personajes de la política tradicional. Viva la FAG!

Contra la clase dominante, anarquismo militante! Arriba lxs que luchan!!!

FAR - Federación Anarquista de Rosario (Argentina)

A Federação Anarquista de Rosário expressa sua profunda solidariedade com nossos irmãos da Federação Anarquista Gaucha que sofre muma brutal perseguição política, maisuma vez, pelo Estado brasileiro e Riograndense. A avançada represiva dos poderosos é inaceitável. O problema da pobreza, desemprego, flexibilidade do trabalho e precarização no Brasil nunca será resolvido pela perseguição daqueles que lutam Semprepela criatividade eluta das organizações populares. Exigimos a cessação lutam. Semprepẽ ça desta persegução absurda e ridicula. Nossos colgas gauchos não são responsáveis pela desiguad em plena disposição para o que voces precisemneste momento difícil provocado por em plena disposição para o que voces precisemneste momento difícil provocado por umpunhado de personagens da política tradicionai.

$$
\begin{aligned}
& \text { Contra la clase dominante, anarquismo militante! } \\
& \text { Arriba Ixs que luchan!!! }
\end{aligned}
$$

FAR - Federación Anarquista de Rosario (Argentina)
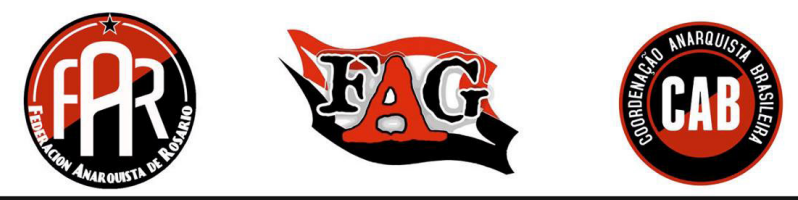

Fonte: Facebook

A partir dos trabalhos de campo realizados, principalmente no que se refere aos discursos dos ativistas, identifico a existência de um ativismo transnacional libertário na região transnacional gaucha.
Esse ativismo transnacional tem por base as Federações Anarquistas de caráter especifistas e não se dá de forma homogênea, conforme expresso no mapa da Figura 2. 
Figura 2 - Mapa do ativismo transnacional libertário na região transnacional gaucha.



Fonte: elaboração do autor sobre cartografia de Isis Martins.

Existem interações transnacionais fortes (caso FAUFAG) e interações transnacionais com menos força ou esparsas (casos FAU-FAR e FAG-FAR) devido aos motivos expostos pelos ativistas. Disso depreendese um particularismo militante anarquista ${ }^{9}$ desde Montevidéu até diversas organizações anarquistas especifistas de outros países sul-americanos, e, especialmente no caso da região transnacional gaucha, tal particularismo é notável. A territorialização de certos espaços como Centros Sociais e Ateneus (sedes das Federações) dão o suporte material para a construção de territórios dissidentes conectados multiescalarmente por redes espaciais que, por sua vez, promovem a transnacionalidade do ativismo. As práticas espaciais insurgentes de construção de territórios dissidentes e de redes espaciais, a partir da tipologia em Souza (2012), seguem uma política na qual as seguintes escalas são particularmente mobilizadas no ativismo transnacional libertário:

${ }^{9}$ Particularismo militante é uma expressão de Raymond Williams (1989) assim sintetizada em Souza (2017, p. 223, nota 126): "partindo-se de identidades, mobilizações e agendas particulares (local ou regionalmente enraizadas), chegar a perceber questões de interesse bastante geral, o que dá ensejo ao enfrentamento decidido de processos e problemas atinentes a forças cujo alcance geográfico é bastante abrangente (...) É a capacidade de um grupo social em conseguir conferir conscientemente uma dimensão 'universal' à sua luta, conquanto tendo como ponto de partida questões e tendo motivações imediatas específicas/locais".
- Escala local: sedes-referência (territórios dissidentes) das Federações Anarquistas, formação política, grupos de estudos, eventos públicos políticos e culturais, inserção nas lutas estudantis, sindicais, comunitárias e de trabalhadores nas mais diversas esferas;

- Escala regional transnacional: fundação de novas organizações, compartilhamento de experiências, ideias, estudos e análises de conjuntura com solidariedade transnacional em épocas de repressão por parte do Estado $^{10}$. Leva à escala nacional do Brasil com a construção da Coordenação Anarquista Brasileira.

Resgatemos agora a ideia de regionofilia. Conforme dito, trata-se de mero "conceito em construção", instrumento desenvolvido para uma pesquisa específica, mas que pode, em futuros trabalhos, ser aprofundado teórico-conceitualmente. Por ora, partamos da consideração simples de que ela remete ao sentimento de pertencimento a uma determinada região. Para o intuito deste texto, avança-se sobre a dimensão política: a regionofilia pode ora dar suporte para um regionalismo (territorialismo, bairrismo, fechamento/enclausuramento

${ }^{0}$ Durante trabalho de campo tive a oportunidade de levar materiais de Porto Alegre para Montevidéu e Rosário, e trazer para o Brasil materiais do Prata, tendo de fato experimentado essa rede transnacional das Federações. 
territorial etc.) como para outras expressões regionofílicas ("pensar o e dialogar com o mundo a partir do seu lugar"). 0 ativismo transnacional em tela, principalmente as falas dos ativistas, trazem elementos que "integram" seus membros via dimensão simbólicocultural. A insubordinação/insubmissão dos gauchos do passado e sua crítica feroz às cercas de propriedades privadas e às fronteiras estatais são apontadas como elementos que podem ser mobilizados no presente, no diálogo com trabalhadoras(es) diversas(os) e mesmo com os próprios ativistas, já que o universo valorativo gaucho ainda se faz presente no imaginário popular.

Visto isso, apesar de que, no contexto da tese que originou o presente artigo, inicialmente se tenha buscado relações entre a identidade sócio-espacial gaucha e o pensamento libertário, a empiria levou a um caminho um pouco diferente. Constatou-se que os principais sustentáculos dessa rede giram em torno da estratégia especifista, sendo os elementos simbólicos gauchos um pano de fundo e algo que os próprios entrevistados acreditam que possa ser melhor explorado. Em todo caso, menções à necessidade de se romper com os nacionalismos e aumentar as trocas transnacionais em direção ao fortalecimento das ações das organizações anarquistas remetem a uma regionofilia libertária, onde a multiescalaridade do ativismo e sua repercussão na escala regional-transnacional são expressões disso.

Considerações finais: regionofilia antinacionalista, regionofilia libertária

A dimensão simbólico-cultural da sociedade não é um mero epifenômeno para se analisar movimentos sociais, ela é fundamental para a compreensão de diversas lutas sociais que não necessariamente se atém ao campo das chamadas lutas identitárias. 0 estudo de caso apresentado demonstrou que a articulação política dos ativistas é catalisada e se transnacionaliza com o auxílio de elementos valorativos comuns, uma história e uma geografia compartilhadas.

As Federações Anarquistas abordadas no recorte espacial estão mais ligadas pela estratégia especifista do que pelo universo valorativo gaucho, sendo este um pano de fundo importante para algumas de suas ações, aparecendo de maneira relativamente secundária. No entanto, constata-se existência de uma regionofilia libertária na região, e um dos suportes político-culturais do ativismo transnacional libertário é uma regionofilia que traz em seu âmago a necessidade de romper com as fronteiras estatais e combater todo e qualquer tipo de nacionalismo. 0 sentimento de pertencimento e de afeição a uma região, no presente caso, não deu suporte para um territorialismo na forma de regionalismo (transnacional) conservador; pelo contrário, fez emergir uma regionofilia antinacionalista, uma regionofilia libertária. 


\section{Referências}

ALVES, D. A. A. (2016) Arriba los que luchan! Sindicalismo revolucionário e luta armada. A trajetória da Federação Anarquista Uruguaia: 1963-1973. Dissertação (Mestrado em História). Porto Alegre: Programa de Pós-Graduação em História - UFRGS.

CORRÊA, F. (2013) Anarquismo especifista. Rio de Janeiro: FARJ, 2013. Disponível em: <https://anarquismorj. wordpress.com/textos-e-documentos/teoria-e-debate/anarquismo-especifista-felipe-correa/>. Acessado em: $1 / 9 / 2017$

ELIAS, N.; SCOTSON, J. (2000 [1994]) Os estabelecidos e os outsiders. Sociologia das relações de poder a partir de uma pequena comunidade. Rio de Janeiro: Zahar.

FEDERACIÓN ANARQUISTA URUGUAYA. (1993) Declaración de Principios. Montevidéu.

SOUZA, M. L. (2012) Challenging Heteronomous Power in a Globalized World: Insurgent Spatial Pratices, "Militant Particularism" and Multiscalarity. In: KRÄKTE, Stefan; WILDNER, Kathrin; LANZ, Stephan (orgs.). Transnationalism and Urbanism. Londres e Nova York: Routledge.

(2017) Por uma geografia libertária. Rio de Janeiro: Consequência.

WILLIAMS, R. (1989) Resources of Hope. Culture, Democracy, Socialism. Londres e Nova York: Verso.

ZILIO, R. (2014) Apontamentos sobre a construção da região transnacional gaucha. In: Entre-Lugar. V. 5, n. 9, p. 59-73. Dourados: UFGD.

(2016) A identidade sócio-espacial gaucha em suas vertentes e espacialidades correspondentes. In: Boletim Gaúcho de Geografia. V. 43, n. 2, p. 60-80. Porto Alegre: Associação dos Geógrafos Brasileiros - Seção Porto Alegre. 